\title{
Assessment of physical activity and inactivity in multiple domains of daily life: a comparison between a computerized questionnaire and the SenseWear Armband complemented with an electronic diary
}

\author{
Tineke Scheers $^{1,2^{*}}$, Renaat Philippaerts ${ }^{3}$ and Johan Lefevre ${ }^{1}$
}

\begin{abstract}
Background: Although differences between paper-and-pencil questionnaires and accelerometers have been reported for overall physical activity and time spent in moderate and vigorous activity, few studies have looked at domain-specific behavior. This study compared estimates of domain-specific physical (in)activity obtained with the Flemish physical activity computerized questionnaire (FPACQ) with those obtained from a combination of the SenseWear Armband and an electronic diary. Furthermore, it was investigated whether the correspondence between the two methods varied with gender and age.

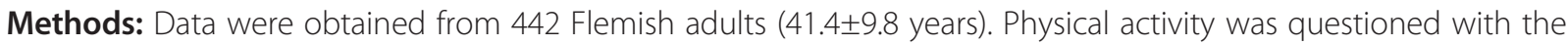
FPACQ and measured for seven consecutive days using the SenseWear Armband together with an electronic activity diary (SWD). Analogous variables were calculated from the FPACQ and SWD. Mean differences and associations between FPACQ and SWD outcomes were examined with paired t-tests and Pearson correlations. The Bland-Altman method was used to assess the level of agreement between the two methods. Main effects and interaction of gender and age groups (20-34; 35-49; 50-64 years) on differences between FPACQ and SWD outcomes were analyzed using two-way ANOVAs.

Results: All parameters of the FPACQ were significantly correlated with SWD assessments ( $r=0.21$ to 0.65 ). Reported activity was significantly different from SWD-obtained values for all parameters, except screen time. Physical activity level, total energy expenditure and time spent in vigorous activities were significantly higher $(+0.14$ MET, +25.09 METhours. week $^{-1}$ and +1.66 hours. week $^{-1}$, respectively), and moderate activities and sedentary

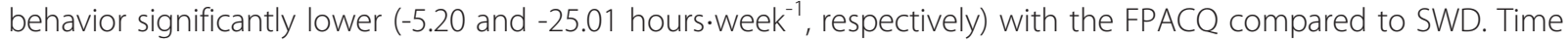
and energy expenditure of job activities and active transport were significantly higher, while household chores, motorized transport, eating and sleeping were significantly lower with the FPACQ. Time spent in sports was lower

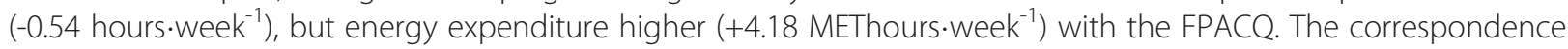
between methods varied with gender and age, but results differed according to the intensity and domain of activity.

(Continued on next page)
\end{abstract}

\footnotetext{
* Correspondence: tineke.scheers@faber.kuleuven.be

'Department of Kinesiology, KU Leuven, Tervuursevest 101, 3001, Leuven, Belgium

${ }^{2}$ Research Foundation, Flanders, Belgium

Full list of author information is available at the end of the article
} 
(Continued from previous page)

Conclusions: Despite the moderate correlations, significant differences between the two methods were found. In general, physical activity was higher and sedentary behavior lower as calculated from the FPACQ compared to SWD.

Keywords: Measurement, Validity, Self-report, Activity monitor, Activities of daily living, Sedentary behavior, Epidemiology

\section{Introduction}

The accurate assessment of physical activity (PA) and sedentary behavior in free-living conditions has always been a challenge in epidemiological research [1]. Continued efforts to improve assessment techniques are critical for systematic advancements of the field [2]. The accurate measurement of PA is important to clarify the strength and nature of the dose-response relation between PA and health, to identify current and changing activity levels within populations, to monitor adherence to activity guidelines and to determine the effectiveness of interventions designed to promote PA [3].

Self-report techniques remain the most widely used method to evaluate activity patterns at population level [4]. Although, over the past decade, activity monitors such as accelerometers are being used more frequently to objectively characterize PA behavior [2,5]. However, both methods have their limitations and when comparing subjective techniques with accelerometry, major discrepancies may emerge.

Significant errors in subjective measures of activity may occur due to several reasons. First, the accuracy of selfreports is often limited by the cognitive demands of recall, social desirability bias and misinterpretation of the questions [6]. Secondly, most questionnaires tend to focus on only one aspect of every day activity, such as work or leisure time. Few have been developed to assess PA and sedentary behavior in all major areas of daily life, namely leisure time, work, household chores and transport $[7,8]$. However, since leisure time PA accounts for only a small proportion of time and energy expenditure (EE) [9], it is unlikely that methods that are restricted to leisure time PA provide an accurate assessment of total daily EE. Third, people engage in a variety of lifestyle activities, which are intermittent and spread throughout the day [1]. While subjects can accurately recall structured bouts of vigorous activity, intended specifically for exercise, they are not as good at recalling routine or spontaneous, light to moderate activities [2,7].

Accelerometers provide objective data about the intensity, frequency and duration of PA, but they cannot assess the type of activity. Furthermore, accelerometers, typically placed on the hip, are unable to detect cycling, isolated arm movements, locomotion on a gradient or the added strain of lifting, carrying or pushing objects.
As a result, PA is likely to be underestimated using accelerometry $[10,11]$.

Thus, due to inaccurate recall, social desirability or omission of lifestyle activities in questionnaires and the inability of accelerometers to detect all activities equally well, both under- and over-reporting of activity in comparison with an accelerometer can occur $[4,12]$.

To address these limitations, improvements in both subjective and objective measurements of PA are needed. Computerized questionnaires, like the Flemish physical activity computerized questionnaire (FPACQ) [13], have the advantage of a greater feeling of privacy and anonymity, compared to traditional written surveys. This results in a more honest reporting of sensitive information and a reduction of social desirability bias [14]. Nevertheless, the literature reveals few studies on the validity of computerized PA questionnaires. Furthermore, in contrast to most questionnaires, the FPACQ assesses PA and sedentary behavior in all domains of daily life.

Activity monitors like the SenseWear Armband, which combine accelerometry with physiological parameters, can improve the accuracy of measurement [15]. However, no single technique can capture all aspects of activity. Only self-reports can provide information on the type of activity [4,7]. Therefore, to allow for a more comprehensive investigation of activity patterns, we complemented the objective assessment through the SenseWear with an electronic activity diary. The combination of these two techniques made it possible to generate (in)activity variables in the same domains as derived from the FPACQ. Thus, in contrast to previous studies, which only used an overall PA score or time spent in moderate and vigorous activities, this study was able to compare subjective and objective measures of PA and sedentary behavior in all domains of daily life.

However, neither the FPACQ, nor the SenseWear is a golden standard for measuring PA. Therefore, we are limited to describing correspondence between both measures. Nevertheless, in the absence of a true criterion method, the SenseWear Armband combined with the electronic diary will be used as reference method.

The purpose of the present study was to compare estimates of domain-specific PA and sedentary behavior obtained with the FPACQ with those obtained from a 
combination of the SenseWear Armband and an electronic diary (SWD). Furthermore, it was investigated whether the correspondence between the two methods varied with gender and age.

\section{Materials and methods Subjects and study design}

Participants were recruited from various companies and different work sectors (private companies, multinationals, education, research, social and welfare services, municipal services and industry) in Flanders, Belgium. Individuals volunteered to participate in the study and provided informed consent prior to participation. The study was approved by the Medical Ethics Committee of the KU Leuven. Subjects received an e-mail with a username and password and were asked to fill in the FPACQ at home via an internet platform. One to two weeks later health parameters were measured and PA monitoring devices were explained and provided to the subjects at their workplace. Subjects were asked to wear the devices 24 hours a day except during water-based activities, for the following 7 days. A total of 442 subjects (212 men and 230 women) between 22 and 64 years (mean age: $41.4 \pm 9.8$ years) participated in the study. To be included in analyses, subjects needed at least six valid monitoring days, including a Saturday and a Sunday [16]. A valid day was considered a day with at least 1368 min of data, which corresponds to $95 \%$ of a 24 -hour period. Valid SenseWear and SWD data were available from 405 and 383 subjects respectively.

\section{Assessment of physical activity The Flemish physical activity computerized questionnaire (FPACQ)}

The FPACQ is a user-friendly computerized questionnaire that collects detailed information about patterns of PA and sedentary behavior in a usual week [13]. Three different versions of the questionnaire were developed to account for differences in lifestyle of population subgroups: students, employed/unemployed people and pensioners. The FPACQ for the employed/unemployed contains 59 to 103 closed-ended questions on demographic parameters (10 items), bouts of moderate and vigorous PA (3 to 6 items), total sedentary time (2 items), occupation (1 to 22 items), transport in leisure time (6 items), watching TV or playing computer games ( 2 items), household chores (3 items), eating ( 1 item), sleeping (1 item) and determinants of PA (29 items). Skip patterns are used to avoid superfluous questions. The web-based version of the questionnaire is available on www.FPACQ.be. At present, the FPACQ is only available in Dutch, but in the near future, French, English and Portuguese versions will be developed.
For the present study, 20 parameters were calculated from the FPACQ. Total sedentary time and bouts of moderate and vigorous PA were calculated from questions based on the short, self-administered version of the International Physical Activity Questionnaire (IPAQ) [17]. Job time represents the time spent on the main and additional occupation. Additionally, percentages of work time doing light, moderate and vigorous activities were questioned. Light activities were assigned a metabolic equivalent (MET) value of 2, moderate activities 3 and vigorous activities 4 . Percentages were multiplied by the total job time and the assigned MET-values to calculate EE during work. Furthermore, subjects were asked to select a maximum of three of their most important sports out of a list of 200 specific sports. The weekly hours spent on these sports were summed to calculate time of sports participation. For each sport, the MET-value was determined using the Compendium of Ainsworth [18] and multiplied by the time spent on this sport. The sum of these multiplications resulted in EE during sports. Screen time is the sum of hours spent on watching TV or playing computer games during weekdays and weekend days. Time of household chores includes time spent on light, moderate and vigorous home and garden activities. These activities were assigned a MET-value of 2.5, 3.5 and 4.5, respectively, to calculate household EE. FPACQ queried about transport on foot and by bike for leisure and commuting to and from work. The results of these questions were summed and multiplied by $4 \mathrm{MET}$ to estimate time and EE of active transport. Similarly, motorized transport was calculated from questions about transport with a car, train, tramcar, bus or motorcycle and a MET-value of 1.5. Time eating and time sleeping represent the hours spent eating and sleeping during a typical week. EE of these activities was estimated using a MET-value of 1.8 and 0.9 , respectively. Finally, two general variables were calculated. Total EE represents the overall weekly $\mathrm{EE}$ and was calculated by summing the EE of all reported activities. Physical activity level (PAL, MET) was subsequently calculated by dividing total EE by 168 (=numbers of hours per week).

\section{The SenseWear Pro 3 Armband}

The SenseWear Pro 3 Armband (BodyMedia, Inc., Pittsburgh, PA, USA) is a multisensor body monitor, worn over the triceps muscle of the right arm. It enables continuous collection of various physiological and movement parameters through multiple sensors, including a two-axis accelerometer and sensors measuring heat flux, galvanic skin response, skin temperature and near body ambient temperature. Data from these sensors are combined with gender, age, body weight and height to estimate EE and PA intensity, using algorithms developed by the manufacturer (SenseWear professional software, version 6.1). 
Anthropometric measurements were obtained in the morning prior to the consecutive seven-day period by trained staff with subjects barefoot and in underwear. Body weight was measured to the nearest $0.1 \mathrm{~kg}$ using a digital scale (Seca, Hamburg, Germany). Height was measured to the nearest $0.1 \mathrm{~cm}$ using a portable anthropometer of Martin (GPM anthropological instruments, Zurich, Switzerland).

\section{The electronic activity diary}

The activity diary software program was developed at the Department of Kinesiology of the KU Leuven and stored in a Palm Z22 Personal Digital Assistant (Palm, Inc., Sunnyvale, CA, USA). The diary consisted of seven main categories: sleeping/resting, personal care, eating/ drinking, job, leisure time, transport and household chores. The last three categories were divided into a number of subcategories, to allow subjects to specify their activity in more detail. Subjects were asked to register their activities in the electronic diary, each time a new activity was started, for the entire seven-day period. Dunton et al. [19] have shown that diaryreported activity levels from a similar Palm handheld computer corresponded well to objective indicators of activity. Furthermore, these diaries are thought to minimize errors associated with coding and recall of activity, because they enable subjects to add real-time information directly into an electronic medium [2]. First, information from the diary was used to substitute missing SenseWear data, due to removal of the Armband. Missing values for sleep were imputed with the mean MET-value and EE of observed sleep during all other nights. Missing data of personal care and swimming were substituted with a constant MET-value and associated EE according to the Compendium of Ainsworth (a MET-value of 2 and 6, respectively) [18]. Furthermore, information from the diary was synchronized with data of the SenseWear to obtain minute-by-minute data of physical (in)activity behavior. As a result, information was available for all four activity dimensions (intensity, duration, frequency and type).

Twenty parameters were calculated from SWD data, analogous to those from the FPACQ. Total EE (METhours.week ${ }^{-1}$ ) was calculated by summing minute-byminute MET-values during the entire week, while PAL (MET) was calculated as the average of MET-values. Furthermore, time spent in different intensity levels

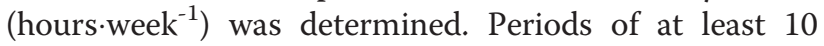
consecutive minutes with an intensity $\geq 3$ but $<6$ and $\geq 6$ MET were summed over the entire week to achieve bouts of moderate and vigorous activity, respectively. Total sedentary time was calculated from minutes with a MET-value $\leq 1.8$ minus minutes spent sleeping. Additionally, time and EE of the different activities in the five domains of daily life were calculated. Time spent doing a particular activity (hours week $^{-1}$ ) was based on the information from the diary, while EE was calculated as weekly METhours during those specific activities, using SWD.

For subjects with only six valid monitoring days, a weekly average was estimated using the following formula: ((mean of parameter over 4 weekdays)*5) + parameter on Saturday + parameter on Sunday.

\section{Statistical analyses}

Descriptive statistics (means and standard deviations) were calculated for all variables. Mean differences in activity variables between the FPACQ and SWD were examined with paired t-tests. Associations between FPACQ and SWD variables were analyzed using Pearson product-moment correlation coefficients. The BlandAltman method was used to assess the level of agreement between the two measurement techniques. Variables used for the Bland-Altman analyses were total EE and EE during job activities, sports, household chores, active transport and motorized transport. Two-way analyses of variance with the difference scores of the FPACQ and SWD outcome (FPACQ outcome - SWD outcome) as dependent variable and gender, age group (20-34; 35-49; 50-64 years) and their interaction as independent variables were performed for each activity parameter. Tukey HSD tests were carried out for post hoc comparisons if significant differences were found. All statistical analyses were performed using the SAS statistical program, version 9.2 (SAS Institute, Cary, NC, USA). Statistical significance was set at $P<0.05$.

\section{Results}

Results of the Pearson correlations and paired t-tests between outcomes of the FPACQ and SWD are shown in Table 1. All parameters of the FPACQ were significantly and positively correlated with SWD values, with correlations varying from 0.21 to 0.65 . Total EE calculated from the FPACQ was moderately correlated with the direct measure of the SenseWear $(r=0.44)$. Concerning time spent in different intensity levels, a moderate correlation was obtained for sedentary behavior $(r=0.54)$, but low correlations were found for moderate and vigorous PA ( $\mathrm{r}=0.27$ and 0.21 , respectively). Regarding time spent in different activity domains, correlations were moderate for job ( $r=0.44$ to 0.45 ), leisure time ( $r=0.57$ to 0.65 ), household chores $(\mathrm{r}=0.39$ to 0.46$)$ and transport $(r=0.49$ to 0.58$)$ and generally low for eating and sleeping $(r=0.26$ to 0.45$)$.

Reported activity was significantly different from SWD-determined values for all parameters, except screen time (Table 1). PAL, total EE and time spent in vigorous activity were significantly higher (+0.14 MET, 
Table 1 Comparison and relationship between FPACQ and SenseWear and/or electronic diary (SWD) parameters (Mean \pm SD)

\begin{tabular}{|c|c|c|c|c|}
\hline & FPACQ & SWD & $P$ & Pearson correlation $^{*}$ \\
\hline \multicolumn{5}{|l|}{ Total physical activity } \\
\hline PAL (MET) & $1.76 \pm 0.23$ & $1.62 \pm 0.25$ & $<0.001$ & 0.44 \\
\hline Total EE (METhours.week ${ }^{-1}$ ) & $296.49 \pm 38.39$ & $271.40 \pm 41.09$ & $<0.001$ & 0.44 \\
\hline Moderate PA (hours.week ${ }^{-1}$ ) & $2.47 \pm 3.02$ & $7.67 \pm 7.14$ & $<0.001$ & 0.27 \\
\hline Vigorous PA (hours.week ${ }^{-1}$ ) & $2.34 \pm 2.68$ & $0.68 \pm 1.23$ & $<0.001$ & 0.21 \\
\hline Sedentary behavior (hours.week ${ }^{-1}$ ) & $37.85 \pm 16.65$ & $62.86 \pm 12.61$ & $<0.001$ & 0.54 \\
\hline \multicolumn{5}{|l|}{ Job } \\
\hline Time (hours.week ${ }^{-1}$ ) & $37.77 \pm 10.12$ & $33.08 \pm 11.40$ & $<0.001$ & 0.44 \\
\hline EE (METhours.week ${ }^{-1}$ ) & $89.12 \pm 26.70$ & $61.39 \pm 25.63$ & $<0.001$ & 0.45 \\
\hline \multicolumn{5}{|l|}{ Leisure time } \\
\hline Time sports (hours.week ${ }^{-1}$ ) & $2.58 \pm 3.44$ & $3.12 \pm 3.45$ & 0.003 & 0.57 \\
\hline EE sports (METhours.week ${ }^{-1}$ ) & $19.04 \pm 29.51$ & $14.86 \pm 17.08$ & $<0.001$ & 0.65 \\
\hline Screen time (hours.week ${ }^{-1}$ ) & $14.65 \pm 7.85$ & $14.70 \pm 9.02$ & 0.648 & 0.57 \\
\hline \multicolumn{5}{|l|}{ Household chores } \\
\hline Time (hours.week ${ }^{-1}$ ) & $10.20 \pm 6.33$ & $15.03 \pm 9.36$ & $<0.001$ & 0.46 \\
\hline EE (METhours.week ${ }^{-1}$ ) & $30.14 \pm 19.71$ & $36.78 \pm 24.03$ & $<0.001$ & 0.39 \\
\hline \multicolumn{5}{|l|}{ Transport } \\
\hline Time active transport (hours.week ${ }^{-1}$ ) & $3.81 \pm 3.87$ & $2.45 \pm 2.61$ & $<0.001$ & 0.49 \\
\hline EE active transport (METhours.week ${ }^{-1}$ ) & $15.24 \pm 15.49$ & $8.21 \pm 9.61$ & $<0.001$ & 0.51 \\
\hline Time motorized transport (hours.week ${ }^{-1}$ ) & $6.33 \pm 4.03$ & $8.99 \pm 4.31$ & $<0.001$ & 0.58 \\
\hline EE motorized transport (METhours.week ${ }^{-1}$ ) & $9.50 \pm 6.04$ & $17.67 \pm 9.03$ & $<0.001$ & 0.52 \\
\hline \multicolumn{5}{|l|}{ Personal care } \\
\hline Time eating (hours.week ${ }^{-1}$ ) & $5.62 \pm 2.42$ & $9.42 \pm 3.62$ & $<0.001$ & 0.26 \\
\hline EE eating (METhours.week ${ }^{-1}$ ) & $10.12 \pm 4.35$ & $15.86 \pm 6.55$ & $<0.001$ & 0.26 \\
\hline Time sleeping (hours.week ${ }^{-1}$ ) & $48.90 \pm 7.01$ & $56.19 \pm 9.39$ & $<0.001$ & 0.45 \\
\hline EE sleeping (METhours.week ${ }^{-1}$ ) & $44.01 \pm 6.31$ & $53.88 \pm 7.96$ & $<0.001$ & 0.36 \\
\hline
\end{tabular}

$\mathrm{EE}$, energy expenditure; $\mathrm{PA}$, physical activity.

Moderate PA: $\geq 3-<6$ MET; Vigorous PA: $\geq 6$ MET; Sedentary behavior: $\leq 1.8$ MET

${ }^{*}$ All correlation coefficients are significant at $P<0.001$.

+25.09 METhours $\cdot$ week $^{-1}$ and +1.66 hours $\cdot$ week $^{-1}$, respectively), and time spent in moderate activity and sedentary behavior significantly lower $(-5.20$ and -25.01 hours.week $^{-1}$, respectively) as calculated from the FPACQ compared to the SenseWear. Time and EE of job activities were significantly higher (+4.69 hours week $^{-1}$ and +27.73 METhours. week $\left.^{-1}\right)$, while household chores (-4.83 hours week ${ }^{-1}$ and -6.64 METhours.week $\left.{ }^{-1}\right)$, eating (-3.80 hours $\cdot$ week $^{-1}$ and -5.74 METhours $\cdot$ week $\left.^{-1}\right)$ and sleeping (-7.29 hours $\cdot$ week $^{-1}$ and -9.87 METhours $\cdot$ week $^{-1}$ ) were significantly lower with FPACQ than with SWD. Time spent in sports was lower $\left(-0.54\right.$ hours $\cdot$ week $\left.^{-1}\right)$, but EE higher (+4.18 METhours. week $^{-1}$ ) with the FPACQ. With regard to transport, reported time and EE of active transport were higher (+1.36 hours week $^{-1}$ and +7.03 METhours'week $\left.{ }^{1}\right)$, while those of motorized transport were lower $(-2.66$ hours $\cdot$ week $^{-1}$ and -8.17 METhours $\cdot$ week $^{-1}$ ), compared to SWD assessments.

The Bland-Altman plots showed that FPACQ resulted in higher total EE for most subjects and throughout the range of values (Figure 1). Although the mean difference was fairly small $(+25.26$ METhours.week $^{-1}$ or $9 \%$ of the average of FPACQ and SenseWear outcomes), 95\% limits of agreement were

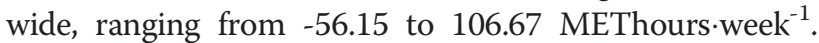
EE during job activities was generally higher, while motorized transport was thoroughly lower with the FPACQ. Mean differences and 95\% limits of agreement between FPACQ and SWD-determined EE were relatively wide for the various activity domains. No systematic bias was observed, except for EE during sports, where the over-reporting by the FPACQ increased with increasing $\mathrm{EE}$. 


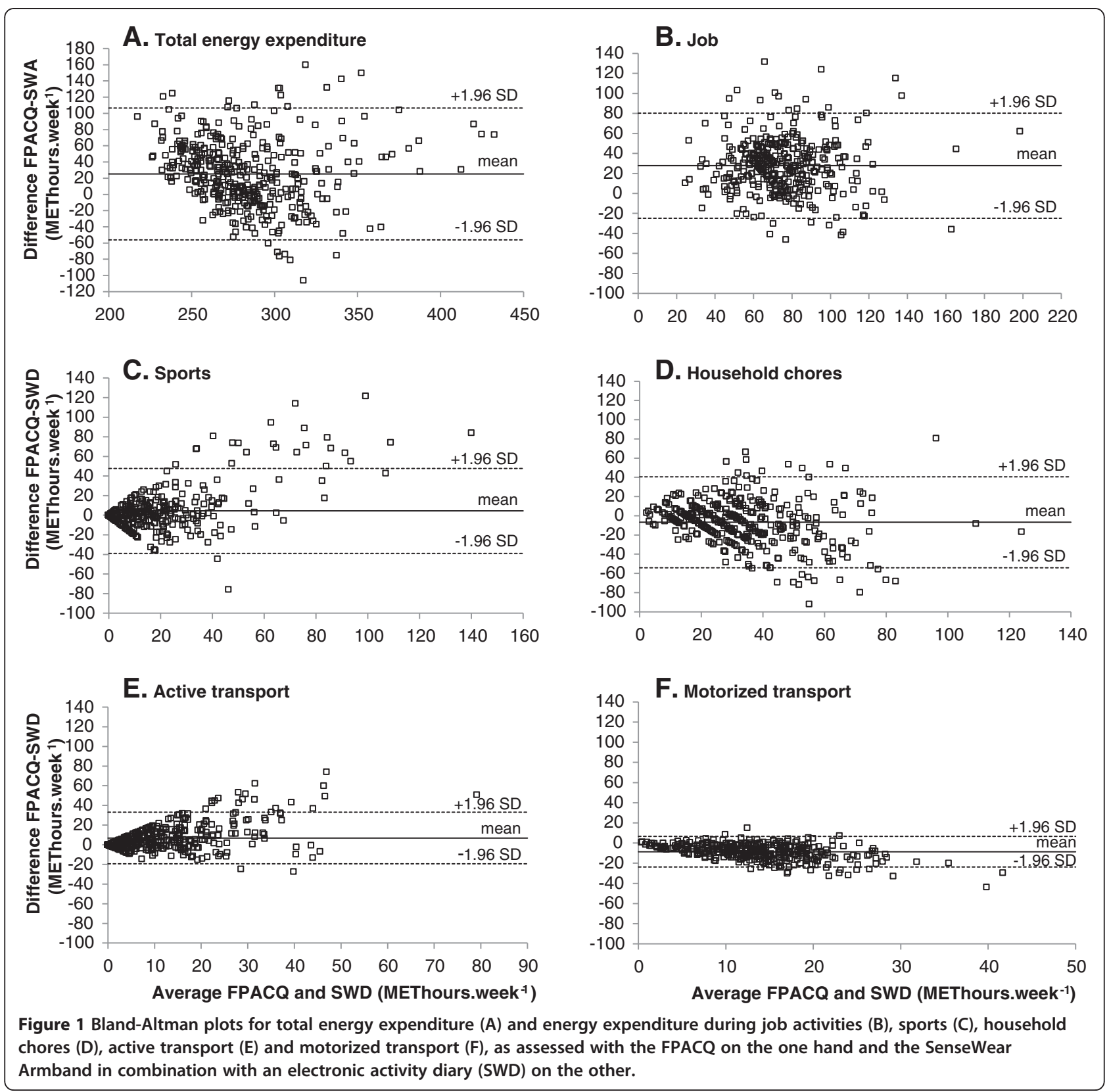

Results of the two-way ANOVA to assess main effects and interaction of gender and age groups on differences between FPACQ and SWD outcomes are presented in Table 2. Time spent in vigorous activities, EE of sports and time and EE of active transport were significantly more over-reported in men, as compared to women. Furthermore, men underreported moderate PA and EE during sleep more, whereas women underreported total sedentary time and household chores to a greater extent. Screen time was underreported by men and slightly over-reported by women. Twenty to 34 year olds had smaller differences between FPACQ and SWD for PAL and total
EE, but greater differences for time spent at moderate activities and EE during sleep than 35-49 and 50-64 year olds. Time spent in vigorous activities was more overreported by young compared to middle-aged adults. Additionally, time during household chores was more underreported, and time and EE during active transport less overreported in the second age group than in the oldest age group.

\section{Discussion}

This study compared estimates of domain-specific PA and sedentary behavior obtained with the FPACQ with those obtained from SWD. Furthermore, it was 
Table 2 Two-way ANOVA for differences between FPACQ and the combination of the SenseWear Armband and electronic diary (FPACQ - SWD outcome) with gender and age

\begin{tabular}{|c|c|c|c|c|c|}
\hline & \multicolumn{2}{|c|}{ Main effect of gender } & \multicolumn{3}{|l|}{ Main effect of age } \\
\hline & men $(n=196)$ & women $(n=209)$ & $20-34$ years $(n=104)$ & $35-49$ years $(n=204)$ & $50-64$ years $(n=97)$ \\
\hline \multicolumn{6}{|l|}{ Total physical activity } \\
\hline PAL (MET) & $0.16 \pm 0.27$ & $0.13 \pm 0.23$ & $0.08 \pm 0.25^{\mathrm{b}, \mathrm{c}}$ & $0.15 \pm 2.26$ & $0.21 \pm 0.21$ \\
\hline Total EE (METhours.week ${ }^{-1}$ ) & $27.64 \pm 44.48$ & $22.89 \pm 38.35$ & $13.98 \pm 41.83^{\mathrm{b}, \mathrm{c}}$ & $26.17 \pm 43.19$ & $35.34 \pm 34.59$ \\
\hline Moderate PA (hours.week ${ }^{-1}$ ) & $-6.91 \pm 7.63^{\mathrm{a}}$ & $-3.61 \pm 5.87$ & $-7.08 \pm 7.68^{\mathrm{b}, \mathrm{c}}$ & $-4.61 \pm 6.72$ & $-4.43 \pm 6.34$ \\
\hline Vigorous PA (hours.week ${ }^{-1}$ ) & $1.93 \pm 2.98^{\mathrm{a}}$ & $1.26 \pm 2.17$ & $2.03 \pm 2.93^{b}$ & $1.28 \pm 2.48$ & $1.76 \pm 2.45$ \\
\hline Sedentary behavior (hours.week ${ }^{-1}$ ) & $-23.00 \pm 14.08^{a}$ & $-26.92 \pm 14.79$ & $-23.45 \pm 14.60$ & $-25.52 \pm 14.53$ & $-25.64 \pm 14.61$ \\
\hline \multicolumn{6}{|l|}{ Job } \\
\hline Time (hours.week ${ }^{-1}$ ) & $5.08 \pm 10.48$ & $4.41 \pm 12.41$ & $5.53 \pm 13.38$ & $4.52 \pm 11.29$ & $4.32 \pm 9.77$ \\
\hline EE (METhours.week ${ }^{-1}$ ) & $30.71 \pm 25.23$ & $24.88 \pm 28.02$ & $23.66 \pm 29.68$ & $30.45 \pm 26.32$ & $26.25 \pm 24.15$ \\
\hline \multicolumn{6}{|l|}{ Leisure time } \\
\hline Time sport (hours.week ${ }^{-1}$ ) & $-0.42 \pm 3.85$ & $-0.56 \pm 2.46$ & $-0.42 \pm 3.05$ & $-0.50 \pm 3.02$ & $-0.55 \pm 3.75$ \\
\hline EE sport (METhours.week ${ }^{-1}$ ) & $8.59 \pm 28.41^{a}$ & $0.48 \pm 12.90$ & $6.50 \pm 23.38$ & $4.28 \pm 21.82$ & $2.26 \pm 21.38$ \\
\hline Screen time (hours.week ${ }^{-1}$ ) & $-1.15 \pm 7.82^{\mathrm{a}}$ & $0.71 \pm 7.82$ & $-0.56 \pm 8.27$ & $0.60 \pm 7.79$ & $-1.49 \pm 7.46$ \\
\hline \multicolumn{6}{|l|}{ Household chores } \\
\hline Time (hours.week ${ }^{-1}$ ) & $-3.38 \pm 8.54^{\mathrm{a}}$ & $-6.20 \pm 8.33$ & $-4.26 \pm 7.95$ & $-5.78 \pm 8.80^{d}$ & $-3.44 \pm 8.40$ \\
\hline EE (METhours.week ${ }^{-1}$ ) & $-4.72 \pm 24.14^{a}$ & $-8.63 \pm 24.08$ & $-7.03 \pm 22.31$ & $-8.75 \pm 23.95$ & $-2.12 \pm 26.07$ \\
\hline \multicolumn{6}{|l|}{ Transport } \\
\hline Time active transport (hours.week ${ }^{-1}$ ) & $1.66 \pm 3.90^{\mathrm{a}}$ & $1.01 \pm 2.94$ & $1.27 \pm 3.66$ & $1.01 \pm 3.30^{d}$ & $2.07 \pm 3.45$ \\
\hline EE active transport (METhours.week ${ }^{-1}$ ) & $8.06 \pm 15.17^{\mathrm{a}}$ & $5.78 \pm 11.49$ & $6.73 \pm 14.14$ & $5.68 \pm 12.89^{d}$ & $9.62 \pm 13.48$ \\
\hline Time passive transport (hours.week ${ }^{-1}$ ) & $-3.00 \pm 3.84$ & $-2.84 \pm 3.70$ & $-2.79 \pm 4.06$ & $-2.92 \pm 3.75$ & $-3.06 \pm 3.51$ \\
\hline EE passive transport (METhours.week ${ }^{-1}$ ) & $-8.98 \pm 9.34$ & $-8.19 \pm 7.19$ & $-9.56 \pm 8.83$ & $-8.42 \pm 7.58$ & $-7.84 \pm 6.87$ \\
\hline \multicolumn{6}{|l|}{ Personal care } \\
\hline Time eating (hours.week ${ }^{-1}$ ) & $-3.69 \pm 3.82$ & $-3.99 \pm 3.77$ & $-3.23 \pm 3.44$ & $-3.90 \pm 3.80$ & $-4.40 \pm 4.07$ \\
\hline EE eating (METhours.week ${ }^{-1}$ ) & $-6.11 \pm 6.84$ & $-5.57 \pm 6.91$ & $-5.57 \pm 6.59$ & $-5.73 \pm 6.73$ & $-6.33 \pm 7.50$ \\
\hline Time sleeping (hours.week ${ }^{-1}$ ) & $-7.20 \pm 7.29$ & $-7.50 \pm 7.10$ & $-8.09 \pm 7.78$ & $-6.83 \pm 6.98$ & $-7.71 \pm 6.94$ \\
\hline EE sleeping (METhours.week ${ }^{-1}$ ) & $-10.87 \pm 7.83^{\mathrm{a}}$ & $-9.06 \pm 8.61$ & $-13.67 \pm 9.40^{b, c}$ & $-9.40 \pm 7.39$ & $-7.06 \pm 7.43$ \\
\hline
\end{tabular}

Data are presented as means \pm standard deviation; EE, energy expenditure; PA, physical activity; Moderate PA: $\geq 3-<6$ MET; Vigorous PA; $\geq 6$ MET; Sedentary behavior: $\leq 1.8 \mathrm{MET}$.

${ }^{a}$ Significant difference between men and women, $P<0.05$.

b Significant difference between age groups $20-34$ and $35-49$ years, $P<0.05$

c Significant difference between age groups $20-34$ and 50-64 years, $P<0.05$.

${ }^{d}$ Significant difference between age groups 35-49 and 50-64 years, $P<0.05$. No interaction effects were observed.

examined whether the correspondence between the two methods varied with gender and age. All parameters of the FPACQ were significantly and positively correlated with SWD-outcomes. Nevertheless, significant differences between both methods were found. In general, PA was higher and sedentary behavior lower with the FPACQ compared to SWD. These results are similar to those of several other studies, which showed that, when compared to objective data obtained from accelerometers, questionnaires have acceptable validity, but generally overestimate PA $[13,20,21]$. However, previous studies are mostly limited to overall PA or time spent at moderate and vigorous activity, whereas the current study highlights the importance of examining domain-specific activity when investigating agreement between measurement techniques.

Correlations between the two methods varied between 0.21 and 0.65 and are similar to what is typically reported for PA questionnaires evaluated in adults $[4,17,22]$. An important contribution of this study is the comparison between subjective and objective measures of physical (in)activity in different domains of daily life. Correlations were moderate for job, leisure time, household chores and transport, but 
low for eating and sleeping. To our knowledge, only two studies divided accelerometer output into different domains according to the information obtained from an activity log, similar to what was done in the current study. Measures of occupational activity from Tecumseh and Baecke questionnaires were significantly correlated with Tracmor output during work $(r=0.26$ to 0.50 ), but low or no correlations were found for indices of active leisure time. However, active leisure time included a wide range of activities, such as sports, household and garden activities [23]. Matton et al. [13] showed comparable correlations for active transport (0.49-0.55), but higher correlations for sports (0.47-0.77), TV viewing (0.69-0.83), occupation (0.78-0.88) and eating and sleeping (0.53-0.69). There were, however, subtle differences in the calculation of the FPACQ parameters.

Despite of the significant correlations, PAL and total EE were significantly higher and sedentary time significantly lower with the FPACQ as compared to the SenseWear. These results are consistent with findings from several previous studies $[4,13,21]$. However, it is unclear whether the differences between the two methods are due to errors in the FPACQ or to inherent limitations of the SenseWear. It has been shown that the SenseWear underestimates total EE by $4 \%$ compared with doubly labeled water $[24,25]$. This could partly explain the observed difference in total EE between FPACQ and SenseWear (9\% of the average of FPACQ and SenseWear outcomes).

With regard to intensity of activity, reported duration of vigorous PA was higher, whereas moderate PA was lower than directly measured by the SenseWear. These complex patterns have been seen in several previous studies. It has been reported that people overestimate the amount of vigorous activity, while underestimating time spent in light and moderate activities [26], though some studies also found an over-reporting of moderate activities [21,27]. The FPACQ questions of time spent in moderate and vigorous PA inquire about overall activity in multiple domains of daily life. These questions are cognitively challenging, because several activities need to be taken into account and summed over the day [28]. Most subjects, asked about PA behavior, seem to think about vigorous or organized activities and not about routine activities like household chores or walking [29]. This underlines the importance of examining domain-specific activity when investigating agreement between measurement techniques. In the current study, time and EE of job activities and active transport were significantly higher and household chores, passive transport, eating and sleeping significantly lower with the FPACQ as compared to SWD.
Furthermore, the FPACQ resulted in lower values for duration, but higher values for EE of sports. Few studies have compared self-reported activity in different domains with similar measures obtained from activity monitors. Matton et al. [13] showed that duration of eating and sleeping and watching TV in women were significantly lower and time and EE of sport, time of active transport and EE during occupation significantly higher when calculated from the FPACQ as compared to an accelerometer plus log. Reported duration of active leisure time was higher in men and slightly, but not significantly, lower in women. However, active leisure time included sports participation, active transport and house and garden activities. This could possibly point to an underreporting of household activities in women, analogous to the current study.

The correspondence between FPACQ and SWD varied with gender and age. However, no clear pattern was observed. Trends differed according to the specific intensity and domain of activity. Men overreported more intense activity significantly more than women, whereas women underreported total sedentary time and household chores to a greater extent. Young adults had smaller differences between FPACQ and SWD for PAL and total EE, but greater differences for time spent at moderate activities than middle-aged and older subjects. Additionally, vigorous activities were more over-reported by young compared to middle-aged adults. The evidence on the role of gender in the agreement between self-report and direct measures of PA has been mixed, with some studies demonstrating better agreement in men $[4,30]$, while others have reported better agreement in women [21,31]. Calabro et al. [32] found that for men, the 24-hour recall estimate of total EE was slightly higher than the SenseWear, whereas for women, it was slightly lower. Only a few studies investigated the impact of age in the accuracy of selfreports. It has been reported that PA questionnaires are especially challenging in older adults because of cognitive processes [33]. Furthermore, a substantial component of their PA, namely activities of daily living, is not captured by most self-report instruments [34]. A review of Ferrari et al. [30] showed that the validity of questionnaires varied with age, with lower coefficients observed for subjects older than 50 years. However, results could differ depending on the questionnaire used [21].

Bland-Altman analyses revealed a relatively small mean difference between FPACQ and SenseWear for total EE. However, 95\% limits of agreement were large, suggesting that there are large individual differences in estimates from both methods. Most of the 
previous studies have reported agreement at the group level, but not at the individual level $[20,35]$. Calabro et al. [32] found a relatively small $(38.5 \mathrm{kcal}$. day $^{-1}$ ), not significant, difference between the 24-hour PA recall and SenseWear for group-level EE. However, differences in individual estimates ranged from -663 to $946 \mathrm{kcal} \cdot \mathrm{day}^{-1}$. In the current study, no systematic bias was observed for total EE. Yet, for sports, a trend towards increased over-reporting by the FPACQ with higher values of EE was found. Other studies also indicated an increased difference with increasing PA. Good agreement existed between IPAQ and ActiGraph up to $1000 \mathrm{~min}$ of PA per week. However, as activity levels increased over $1000 \mathrm{~min}$, the IPAQ tended to overestimate total PA [21]. Bland-Altman plots for the 24-hour recall versus the IDEEA and SenseWear illustrated a tendency of the 24-hour recall to underreport total EE in the least active and over-report in the most active subjects [32].

Several reasons could explain the disagreement between both measurement methods. Social desirability may at least partially explain the over-reporting of PA and underreporting of sedentary pursuits [6]. It has been shown that, over a seven-day period, social desirability bias is associated with over-reporting of PA by approximately $4-11 \mathrm{~min} \cdot \mathrm{day}^{-1}$ [36].

A higher perceived intensity than objectively measured may also lead to differences [37,38]. Some questionnaires, including the FPACQ, ask about activities where physiological parameters like increased sweating, heart rate or breathlessness mark the intensity [1]. However, the perception of intensity depends on the age, gender and fitness of the person as well as on duration of activity [1,2]. Moderate activities could be perceived as vigorous, which may explain the over-reporting of vigorous and underreporting of moderate PA. Likewise, subjects could have overestimated the intensity of their occupational activities, resulting in higher EE in the FPACQ.

A third explanation might be the problems associated with recalling light to moderate activities of daily living. It has been shown that it is difficult to achieve accurate measures of light to moderate PA using self-reports, probably due to their unstructured and intermittent nature [2]. Aadahl et al. [39] have reported that subjects knew quite accurately how much time they slept, worked or watched TV, and how much time they spent on vigorous activities such as sports or heavy gardening. But, the duration of light activities at home was very difficult to remember. This could explain why particularly women underreported the duration of household chores. It is possible that women performed lighter activities, whereas men performed heavier gardening. Additionally, it may be that women accumulated intermittent household chores over the course of the day, whereas chores of men were more structured, making them easier to recall.

Another source of variability may be the result of algorithms used to convert activity data into EE $[10,11,31]$. The SenseWear estimates EE based on physiological and movement parameters, whereas the FPACQ relies on MET-values from a published compendium [18]. Reported activities were converted into an estimate of EE by assigning each activity a specific MET-value. Thus, a single estimate of the energy cost of a certain activity was used for all subjects. This does not allow for individual differences in $\operatorname{EE}[1,2,18]$. However, evidence suggests that there is considerable inter- and intra-individual variability in the energy cost of activities, depending on the person's sex, age, body mass, movement efficiency and environmental conditions in which the activity is performed $[6,40]$. It is remarkable that $\mathrm{EE}$ of sports was highly overreported for men, but not for women. This could point to a potential overestimation of MET-values of certain sports, perhaps those with a higher intensity or those mainly practiced by men. However, it is also known that the SenseWear underestimates EE during very vigorous activities [41,42].

It is important to recognize that the disagreement is a result of limitations in both methods. The reported disagreement in literature may be related to limitations in the use of accelerometers. Part of the overestimation of PA in self-reports may be explained by activities that are not detected with accelerometers [37]. In addition, the wear-time of accelerometers varies between studies and is generally low, for example minimum 10 hours per day [20,34]. However, adults could be awake for up to 16 hours. Thus, during some of the time that the subjects were awake, activities were not registered. It is likely that this produced some bias in the data $[12,43]$. The SenseWear can address some of these limitations. By combining accelerometry with physiological sensors, it can detect the increased EE associated with cycling, upper body movement, carrying loads and walking on an incline [15]. Moreover, in this study, the wear time was standardized to 24 hours a day. However, the SenseWear is not without limitations. Similar to other activity monitors, it is known to overestimate EE of moderate activities and underestimate (very) vigorous and total EE [25,41,42]. Johannsen et al. [24] have noted that the SenseWear underestimated PA EE by $12.5 \%$ compared to estimates derived from doubly labeled water. This may have contributed to the observed differences between FPACQ and SWD for total EE and the EE of sports and active transport. Furthermore, the Armband cannot be worn during water-based activities. 
However, in this study, a constant MET-value was imputed to account for swimming and showering or bathing. Because of these limitations, under- or overestimation by the FPACQ can neither be confirmed nor refused and real activity levels probably lie between the subjective and objective assessments.

Some results might reflect limitations in the use of the diary. First, participants may forget to record short-during activities, such as active transport, leading to an underreporting of these activities in the diary. Second, contrary to what was expected, screen time was not different between methods. Yet, the pattern is complex, as men underreported and women slightly over-reported screen time. This could be due to the following difference. In the diary, subjects were forced to choose between activities, when several activities were performed simultaneously, whereas in the FPACQ, both activities could be reported. For example, when eating a meal in front of TV, subjects could have inserted eating into the diary, whereas they also counted this period of TV-viewing when answering the screen time question in the FPACQ. Also surprisingly, time spent on sports was lower in the FPACQ, as compared to the diary. Indicated hours of sports participation in the diary might include time devoted to changing, refreshment and socializing [6]. Furthermore, subjects knew they participated in a PA study and were monitored for their activity. Thus, because of a possible Hawthorne effect, participants could have performed more sports than usual, resulting in higher values in the diary. This points to a potential restriction of the study. The FPACQ assessed activity during a usual week, where SWD measured last week activity. This could, at least in part, explain the difference in job time between both methods. Subjects could have been monitored during a week with some vacation days or less work time than usual. However, the interpretation of a usual week is difficult and participants sometimes recall the last 7 days as a usual week $[17,28]$.

Some other limitations should be considered when evaluating the results of this study. Participants volunteered to take part in the study. This may have led to a selection bias as most participants were highlyeducated and had white-collar functions. Accordingly, the generalizability of these findings to the general working population may be restricted. Though, a previous study showed that agreement between self-reported and accelerometer-obtained PA did not differ between educational levels [20].

The current study investigated whether the correspondence between recalled and direct measures of PA varied with gender and age. However, trends in agreement may be influenced by several other characteristics, including BMI and cardiovascular fitness $[27,31,37]$. Additional research is needed to identify whether, and to what extent, these factors are associated with reporting bias.

A major strength of this study is the combination of the SenseWear Armband, a valid activity monitor [24,25], with the electronic diary. Each minute of SenseWear data was linked to the diary reported type of activity. In this way, activity variables from the questionnaire could be compared with an objective measure generated in the same dimension, thereby moving beyond examinations of overall PA or time spent at moderate and vigorous intensity. In addition, compared to previous studies examining agreement between measurement techniques [8], this study included a relatively large sample of men and women of diverse ages. Furthermore, the compliance for wearing the SenseWear and completing the diary was very high and only subjects with at least six days with a minimum of 22 hours and $48 \mathrm{~min}$ ( $95 \%$ of 24 hours) of data were included in the analyses.

The current results show that great care must be taken when interpreting self-reported and objectively measured PA. Clearly, the two assessment techniques are not interchangeable. Both instruments capture different aspects of a complex behavior. Activity monitors like the SenseWear, measure motion or movement, while questionnaires provide a behavioral description of activity patterns. As shown previously, subjective and objective methods are independently associated with health parameters, and in that way, self-reports should be used as an addition to objective indicators of movement [44]. Furthermore, it is important to recognize that the current recommendation to accumulate 30 min of PA on most days, is based on associations between self-reported PA and health outcomes. The magnitude of these associations may be severely attenuated by measurement error [30] and less than $30 \mathrm{~min}$ of PA as measured by an accelerometer, may provide significant health benefits [5]. Thus, the benefits of PA may even be greater than what is typically reported.

\section{Conclusions}

In conclusion, our results show a moderate correspondence between FPACQ and SWD. Despite the moderate correlations, significant differences between both methods were found. In general, PA was higher and sedentary behavior lower as calculated from the FPACQ, compared to SWD. Furthermore, correspondence varied with gender and age. Though, no clear patterns emerged. Results differed according to the specific intensity and domain of activity.

\section{Appendix}

The appendix can be seen in Table 3. 
Table 3 Physical (in)activity parameters calculated from the FPACQ and the combination of the SenseWear Armband and electronic diary (SWD)

\begin{tabular}{|c|c|}
\hline Parameter & Questions and responses in the FPACQ \\
\hline \multirow[t]{2}{*}{$\begin{array}{l}\text { Sedentary behavior } \\
\text { (hours.week }^{-1} \text { ) }\end{array}$} & $\begin{array}{l}\text { How much time do you usually spend sitting } \\
\text { on a weekday/weekend day? This may include } \\
\text { time spent sitting at a desk, visiting friends, } \\
\text { reading, studying or watching television. }\end{array}$ \\
\hline & $\rightarrow \underline{\text { Response: }}<30$ min.day $^{-1}$ to $\geq 10$ hours.day $^{-1}$ \\
\hline \multirow[t]{4}{*}{$\begin{array}{l}\text { Moderate physical } \\
\text { activity (hours.week }{ }^{-1} \text { ) }\end{array}$} & $\begin{array}{l}\text { 1) During a usual week, on how many days do } \\
\text { you do moderate physical activities? Moderate } \\
\text { activities refer to activities that take moderate } \\
\text { physical effort and make you breathe somewhat } \\
\text { harder than normal, like carrying light loads, } \\
\text { bicycling at a regular pace, or doubles tennis. } \\
\text { Do not include walking. Think only about those } \\
\text { activities that you did for at least } 10 \text { min at a } \\
\text { time. }\end{array}$ \\
\hline & $\rightarrow$ Response: 0 to 7 days.week ${ }^{-1}$ \\
\hline & $\begin{array}{l}\text { 2) How much time do you usually spend doing } \\
\text { moderate physical activities on one of those } \\
\text { days? }\end{array}$ \\
\hline & $\rightarrow$ Response: 10 to $\geq 120$ min.day $^{-1}$ \\
\hline \multirow[t]{4}{*}{$\begin{array}{l}\text { Vigorous physical activity } \\
\text { (hours.week }^{-1} \text { ) }\end{array}$} & $\begin{array}{l}\text { 1) During a usual week, on how many days do } \\
\text { you do vigorous physical activities? Vigorous } \\
\text { activities refer to activities that take hard } \\
\text { physical effort and make you breathe much } \\
\text { harder than normal, like heavy lifting, digging, } \\
\text { aerobics or fast bicycling. Think only about } \\
\text { those activities that you did for at least } 10 \text { min } \\
\text { at a time. }\end{array}$ \\
\hline & $\rightarrow$ Response: 0 to 7 days.week ${ }^{-1}$ \\
\hline & $\begin{array}{l}\text { 2) How much time do you usually spend doing } \\
\text { vigorous physical activities on one of those } \\
\text { days? }\end{array}$ \\
\hline & $\rightarrow$ Response: 10 to $\geq 120$ min.day $^{-1}$ \\
\hline
\end{tabular}

Number of days with vigorous activities * hours per day spent on vigorous activities

\section{Calculation of SWD} parameters

(Hours spent sitting on a weekday * 5) + (hours spent sitting on a weekend day * 2)

Number of days with moderate activities * hours per day spent on moderate activities
Sum of all minutes with a MET-value $\leq 1.8$ MET minus minutes spent sleeping

Sum of all bouts of at least 10 min with a MET-value $\geq 3$ but $<6$
Sum of all bouts of at least 10 min with a MET-value $\geq 6$
Total EE (METhours.week ${ }^{-1}$ )

1) $E E$ of remaining inactive leisure time $=(168-$ time job - time sports - time household chores time active transport - time motorized transport - time eating - time sleeping) ${ }^{*} 1.5 \mathrm{MET}$

2) $\mathrm{EE} \mathrm{job}+\mathrm{EE}$ sports + EE household chores + EE active transport + EE motorized transport + EE eating $+E E$ sleeping + EE remaining inactive leisure time

PAL (MET)

Time job (hours.week ${ }^{-1}$ )

EE job (METhours.week ${ }^{-1}$ )
How many hours a week do you usually spend doing your main/additional occupation? $\rightarrow$ Response: 0-5 to $>60$ hours.week $^{-1}$

During a usual week at your main/additional occupation, what percentage of the time do you engage in 1) light activities (sitting, standing without lifting or carrying weights,...), 2) moderate activities (lifting or carrying weights, walking continuously,...), 3) vigorous activities (lifting or carrying moderate to heavy weights, construction worker,...)
Total EE/168

Hours per week spent on main occupation + hours per week spent on additional occupation

(Hours spent on main occupation * $\%$ light * 2 MET) + (hours spent on main occupation * \% moderate * 3 MET) + (hours spent on main occupation * $\%$ vigorous * $4 \mathrm{MET})+$ (hours spent on additional occupation * $\%$ light * 2 MET) + (hours spent on additional occupation * \%
Sum of min-by-min METvalues over the entire week
Average of min-by-min METvalues over the entire week

Sum of all minutes reported as 'job' in the electronic diary

Sum of min-by-min METvalues where the indicated activity was 'job' 
Table 3 Physical (in)activity parameters calculated from the FPACQ and the combination of the SenseWear Armband and electronic diary (SWD) (Continued)

$\rightarrow$ Response: 0 to 100\% for each of the three intensity levels

Time sports (hours.week ${ }^{-1}$ )

1) What is your most important sport?

$\rightarrow$ Response: list of 200 different sports

2) How frequently do you perform your most important sport?

$\rightarrow$ Response: 1 week.year ${ }^{-1}$ to $>7$ times per week

3) How much time do you spend on your most important sport?

$\rightarrow$ Response: $<7$ hours during 1 week.year ${ }^{-1}$ to $>2 \overline{\text { hours.week }}^{-1}$

4) How many months a year do you practice your most important sport?

$\rightarrow$ Response: 1 to 12 months per year

Same four questions for the second and third most important sport

EE sports

(METhours.week ${ }^{-1}$ )

Screen time (hours.week ${ }^{-1}$ ) How many hours do you usually spend watching TV/video or playing computer games on a weekday/weekend day?

$\rightarrow$ Response: 0 to $\geq 6$ hours.day ${ }^{-1}$

Time household chores (hours.week $^{-1}$ )

EE household chores (METhours.week ${ }^{-1}$ )

Time active transport (hours.week $^{-1}$ )

How many hours a week do you usually spend doing home or garden activities of 1 ) light intensity (cooking, ironing, watering flowers,...), 2) moderate intensity (vacuuming, mowing lawn,...), 3) vigorous intensity (scrubbing, digging,...

$\rightarrow$ Response: 0 to $>14$ hours.week $^{-1}$

1) How many days a week do you usually walk to and from your main/additional occupation? moderate * 3 MET) + (hours spent on additional occupation * \% vigorous * 4 MET)

1) Conversion of the reported duration of the first, second and third sport into average hours per week over one year

Sum of all minutes reported as 'sports' in the electronic diary (All separately indicated sports were combined)

2) Hours per week spent on first sport + hours per week spent on second sport + hours per week spent on third sport

(Hours per week spent on first sport * MET-value first sport) + (hours per week spent on second sport * MET-value second sport) + (hours per week spent on third sport * MET-value third sport)

(Hours per day spent on a weekday * 5) + (hours per day spent on a weekend day* 2)

Hours per week spent on light household chores + hours per week spent on moderate household chores + hours per week spent on vigorous household chores

(Hours per week spent on light household chores * $2.5 \mathrm{MET}$ ) + (hours per week spent on moderate chores * 3.5 MET) + (hours per week spent on vigorous chores * $4.5 \mathrm{MET}$ )

$\rightarrow$ Response: 0 to 7 days.week ${ }^{-1}$
Sum of min-by-min METvalues where the indicated activity was 'sports'

Sum of all minutes reported as 'watching TV/movies' and 'playing or working on the computer for leisure' in the electronic diary

Sum of all minutes reported as 'in-house activities' and 'garden activities' in the electronic diary

Sum of min-by-min METvalues where the indicated activity was 'in-house activities' or 'garden activities'

Sum of all minutes reported as 'transportation on foot' and 'transportation by bike' in the electronic diary
(Number of days * hours per day spent on walking to and from main occupation) + (number of days * hours per day spent on walking to and from additional occupation) + (number of days * hours per day spent on cycling to and from main occupation) + (number of days * hours per day spent on cycling to and from additional occupation) + (hours per weekday spent on transportation on foot in leisure time* ${ }^{*}$ ) + (hours per weekday 
Table 3 Physical (in)activity parameters calculated from the FPACQ and the combination of the SenseWear Armband and electronic diary (SWD) (Continued)

EE active transport (METhours.week-1)

Time motorized transport (hours.week-1)

EE motorized transport (METhours.week- ${ }^{-}$)

Time eating (hours.week- ${ }^{-1}$ )

EE eating

(METhours.week- ${ }^{1}$ )

Time sleeping

(hours.week-1)

EE sleeping

(METhours.week-1)

spent on transportation by bike in leisure time * 5) + (hours per weekend day spent on transportation on foot in leisure time $\left.{ }^{*} 2\right)+($ hours per weekend day spent on transportation by bike in leisure time ${ }^{*} 2$ )

2) How many minutes do you usually walk to and from your main/ additional occupation on such days?

$\rightarrow$ Response: 0-10 to $>120$ min.day $^{-1}$

3) In leisure time, how many minutes do you usually spend on transportation on foot, on a weekday/weekend day?

$\rightarrow$ Response: no transportation in this way to $>120$ min. $_{\text {day }}{ }^{-1}$

Same three questions for transportation by bike

1) How many days a week do you usually make use of a car, train, tramcar, bus or motorcycle for commuting to and from your main/ additional occupation?

$\rightarrow$ Response: 0 to 7 days.week- ${ }^{1}$

2) How many minutes do you usually spend on transportation by car, train, tramcar, bus or motorcycle to and from your main/additional occupation on such days?

$\rightarrow$ Response: 0-10 to $>120$ min.day- $^{1}$

3) In leisure time, how many minutes do you usually spend on transportation by car, train, tramcar, bus or motorcycle on a weekday/ weekend day?

$\rightarrow$ Response: no transportation in this way

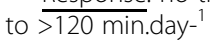

How many minutes a day to you usually spend eating your daily meals?

$\rightarrow$ Response: $0-10$ to $>120$ min.day- $^{-1}$

(Number of days * hours per day spent on motorized transport to and from main occupation) + (number of days * hours per day spent on motorized transport to and from additional occupation) + (hours per weekday spent on motorized transport in leisure time *5) + (hours per weekend day spent on motorized transport in leisure time ${ }^{*}$ )

Time motorized transport * $1.5 \mathrm{MET}$

Hours per day spent eating *7

Time eating * 1.8 MET

Hours per night spent sleeping * 7

How many hours a night do you usually spend sleeping?

$\rightarrow$ Response: $<5$ to $>12$ hours.night- ${ }^{1}$
Sum of min-by-min METvalues where the indicated activity was 'transportation on foot' or 'transportation by bike'

Sum of all minutes reported as 'motorized transport' in the electronic diary
Sum of min-by-min METvalues where the indicated activity was 'motorized transport'

Sum of all minutes reported as 'eating/drinking' in the electronic diary

Sum of min-by-min METvalues where the indicated activity was 'eating/drinking'

Sum of all minutes reported as 'sleeping/resting' in the electronic diary

Sum of min-by-min METvalues where the indicated activity was 'sleeping' 


\section{Competing interests}

The authors declare that they have no competing interests.

\section{Authors' contributions}

TS contributed to the design of the study, collected, analyzed and interpreted the data and drafted the manuscript; RP participated in the coordination of the study and revised the manuscript critically for intellectual content. $J$ conceived the study, helped with statistical analyses and interpretation of the data and had general supervision of the study. All authors critically read and gave final approval of the version to be published.

\section{Acknowledgements}

T. Scheers was funded by the Research Foundation - Flanders.

\section{Author details}

${ }^{1}$ Department of Kinesiology, KU Leuven, Tervuursevest 101, 3001, Leuven, Belgium. ${ }^{2}$ Research Foundation, Flanders, Belgium. ${ }^{3}$ Department of Movement and Sport Sciences, Ghent University, Watersportlaan 2, 9000, Ghent, Belgium.

Received: 16 October 2011 Accepted: 30 May 2012

Published: 12 June 2012

\section{References}

1. Lagerros YT, Lagiou P: Assessment of physical activity and energy expenditure in epidemiological research of chronic diseases. Eur J Epidemiol 2007, 22:353-362.

2. Welk GJ: Physical activity assessments for health-related research. Champaign: Human kinetics; 2002

3. Wareham NJ, Rennie KL: The assessment of physical activity in individuals and populations: why try to be more precise about how physical activity is assessed? Int J Obes Relat Metab Disord 1998, 22(Suppl 2):S30-S38.

4. Prince SA, Adamo KB, Hamel ME, Hardt J, Gorber SC, Tremblay M: A comparison of direct versus self-report measures for assessing physical activity in adults: a systematic review. Int J Behav Nutr Phys Act 2008, 5:56-80.

5. Troiano RP, Berrigan D, Dodd KW, Masse LC, Tilert T, McDowell M: Physical activity in the United States measured by accelerometer. Med Sci Sports Exerc 2008, 40:181-188

6. Shephard RJ: Limits to the measurement of habitual physical activity by questionnaires. Br J Sports Med 2003, 37:197-206.

7. Sallis JF, Saelens BE: Assessment of physical activity by self-report: status, limitations, and future directions. Res Q Exerc Sport 2000, 71:S1-S14.

8. van Poppel MN, Chinapaw MJ, Mokkink LB, van Mechelen W, Terwee CB: Physical activity questionnaires for adults: a systematic review of measurement properties. Sports Med 2010, 40:565-600.

9. Dong L, Block G, Mandel S: Activities Contributing to Total Energy Expenditure in the United States: Results from the NHAPS Study. Int J Behav Nutr Phys Act 2004, 1:4-15.

10. Hendelman D, Miller K, Baggett C, Debold E, Freedson P: Validity of accelerometry for the assessment of moderate intensity physical activity in the field. Med Sci Sports Exerc 2000, 32:S442-S449.

11. Bassett DR Jr, Ainsworth BE, Swartz AM, Strath SJ, O'Brien WL, King GA: Validity of four motion sensors in measuring moderate intensity physical activity. Med Sci Sports Exerc 2000, 32:S471-S480.

12. Leenders NY, Sherman WM, Nagaraja HN, Kien CL: Evaluation of methods to assess physical activity in free-living conditions. Med Sci Sports Exerc 2001, 33:1233-1240.

13. Matton L, Wijndaele K, Duvigneaud N, Duquet W, Philippaerts R, Thomis M, Lefevre J: Reliability and validity of the Flemish Physical Activity Computerized Questionnaire in adults. Res Q Exerc Sport 2007, 78:293-306.

14. Turner CF, Ku L, Rogers SM, Lindberg LD, Pleck JH, Sonenstein FL: Adolescent sexual behavior, drug use, and violence: increased reporting with computer survey technology. Science 1998, 280:867-873.

15. Welk GJ, McClain JJ, Eisenmann JC, Wickel EE: Field validation of the MTI Actigraph and BodyMedia armband monitor using the IDEEA monitor. Obesity (Silver Spring) 2007, 15:918-928.

16. Scheers $T$, Philippaerts $R$, Lefevre J: Variability in physical activity patterns as measured by the SenseWear Armband: how many days are needed? Eur J Appl Physiol 2012, 112:1653-1662.

17. Craig CL, Marshall AL, Sjostrom M, Bauman AE, Booth ML, Ainsworth BE, Pratt $M$, Ekelund U, Yngve A, Sallis JF, et al: International physical activity questionnaire: 12-country reliability and validity. Med Sci Sports Exerc 2003, 35:1381-1395.

18. Ainsworth BE, Haskell WL, Whitt MC, Irwin ML, Swartz AM, Strath SJ, O'Brien WL, Bassett DR Jr, Schmitz KH, Emplaincourt PO, et al: Compendium of physical activities: an update of activity codes and MET intensities. Med Sci Sports Exerc 2000, 32:S498-S504.

19. Dunton GF, Whalen CK, Jamner LD, Henker B, Floro JN: Using ecologic momentary assessment to measure physical activity during adolescence. Am J Prev Med 2005, 29:281-287.

20. Ekelund U, Sepp H, Brage S, Becker W, Jakes R, Hennings M, Wareham NJ: Criterion-related validity of the last 7-day, short form of the International Physical Activity Questionnaire in Swedish adults. Public Health Nutr 2006, 9:258-265.

21. Boon RM, Hamlin MJ, Steel GD, Ross JJ: Validation of the New Zealand Physical Activity Questionnaire (NZPAQ-LF) and the International Physical Activity Questionnaire (IPAQ-LF) with accelerometry. Br J Sports Med 2010, 44:741-746.

22. Vandelanotte C, De Bourdeaudhuij I, Philippaerts R, Sjöström M, Sallis J: Reliability and validity of a computerized and Dutch version of the International Physical Activity Questionnaire (IPAQ). J Phys Act Health 2005, 63-75.

23. Philippaerts RM, Westerterp KR, Lefevre J: Comparison of two questionnaires with a tri-axial accelerometer to assess physical activity patterns. Int J Sports Med 2001, 22:34-39.

24. Johannsen DL, Calabro MA, Stewart J, Franke W, Rood JC, Welk GJ: Accuracy of armband monitors for measuring daily energy expenditure in healthy adults. Med Sci Sports Exerc 2010, 42:2134-2140.

25. St-Onge M, Mignault D, Allison DB, Rabasa-Lhoret R: Evaluation of a portable device to measure daily energy expenditure in free-living adults. Am J Clin Nutr 2007, 85:742-749.

26. Besson H, Brage S, Jakes RW, Ekelund U, Wareham NJ: Estimating physical activity energy expenditure, sedentary time, and physical activity intensity by self-report in adults. Am J Clin Nutr 2010, 91:106-114.

27. Timperio A, Salmon J, Crawford D: Validity and reliability of a physical activity recall instrument among overweight and non-overweight men and women. J Sci Med Sport 2003, 6:477-491.

28. Yore MM, Ham SA, Ainsworth BE, Kruger J, Reis JP, Kohl HW III, Macera CA: Reliability and validity of the instrument used in BRFSS to assess physical activity. Med Sci Sports Exerc 2007, 39:1267-1274.

29. Jacobs DR Jr, Ainsworth BE, Hartman TJ, Leon AS: A simultaneous evaluation of 10 commonly used physical activity questionnaires. Med Sci Sports Exerc 1993, 25:81-91.

30. Ferrari $P$, Friedenreich $C$, Matthews CE: The role of measurement error in estimating levels of physical activity. Am J Epidemiol 2007, 166:832-840.

31. Washburn RA, Jacobsen DJ, Sonko BJ, Hill JO, Donnelly JE: The validity of the Stanford Seven-Day Physical Activity Recall in young adults. Med SCi Sports Exerc 2003, 35:1374-1380.

32. Calabro MA, Welk GJ, Carriquiry AL, Nusser SM, Beyler NK, Mathews CE: Validation of a computerized 24-hour physical activity recall (24PAR) instrument with pattern-recognition activity monitors. J Phys Act Health 2009, 6:211-220.

33. Rikli RE: Reliability, validity, and methodological issues in assessing physical activity in older adults. Res Q Exerc Sport 2000, 71:S89-S96.

34. Colbert LH, Matthews CE, Havighurst TC, Kim K, Schoeller DA: Comparative validity of physical activity measures in older adults. Med Sci Sports Exerc 2011, 43:867-876.

35. Hagstromer M, Oja P, Sjostrom M: The International Physical Activity Questionnaire (IPAQ): a study of concurrent and construct validity. Public Health Nutr 2006, 9:755-762.

36. Adams SA, Matthews CE, Ebbeling CB, Moore CG, Cunningham JE, Fulton J, Hebert JR: The effect of social desirability and social approval on selfreports of physical activity. Am J Epidemiol 2005, 161:389-398.

37. Slootmaker SM, Schuit AJ, Chinapaw MJ, Seidell JC, van Mechelen W: Disagreement in physical activity assessed by accelerometer and selfreport in subgroups of age, gender, education and weight status. Int J Behav Nutr Phys Act 2009, 6:17.

38. Duncan GE, Sydeman SJ, Perri MG, Limacher MC, Martin AD: Can sedentary adults accurately recall the intensity of their physical activity? Prev Med 2001, 33:18-26.

39. Aadahl M, Jorgensen T: Validation of a new self-report instrument for measuring physical activity. Med Sci Sports Exerc 2003, 35:1196-1202. 
40. Levine JA: Measurement of energy expenditure. Public Health Nutr 2005, 8:1123-1132.

41. Berntsen S, Hageberg R, Aandstad A, Mowinckel P, Anderssen SA, Carlsen $\mathrm{KH}$, Andersen LB: Validity of physical activity monitors in adults participating in free-living activities. Br J Sports Med 2010, 44:657-664.

42. Drenowatz C, Eisenmann JC: Validation of the SenseWear Armband at high intensity exercise. Eur J Appl Physiol 2011, 111:883-887.

43. Masse LC, Fuemmeler BF, Anderson CB, Matthews CE, Trost SG, Catellier DJ, Treuth M: Accelerometer data reduction: a comparison of four reduction algorithms on select outcome variables. Med Sci Sports Exerc 2005, 37:S544-S554

44. Atienza AA, Moser RP, Perna F, Dodd K, Ballard-Barbash R, Troiano RP, Berrigan D: Self-reported and objectively measured activity related to biomarkers using NHANES. Med Sci Sports Exerc 2011, 43:815-821.

doi:10.1186/1479-5868-9-71

Cite this article as: Scheers et al: Assessment of physical activity and inactivity in multiple domains of daily life: a comparison between a computerized questionnaire and the SenseWear Armband

complemented with an electronic diary. International Journal of Behavioral Nutrition and Physical Activity 2012 9:71.

\section{Submit your next manuscript to BioMed Central and take full advantage of:}

- Convenient online submission

- Thorough peer review

- No space constraints or color figure charges

- Immediate publication on acceptance

- Inclusion in PubMed, CAS, Scopus and Google Scholar

- Research which is freely available for redistribution 